\title{
Epidemiology of Deaths by Lightning in the State of Sao Paulo-Brazil Years 2000 to 2014, and Impacts of Development and Environmental Factors Nery $T^{*}$, Pereira $F$ and Christensen $R$
}

Secretary of State for Health-Epidemiological Surveillance Center, Division of Diseases Caused by Environmental, SP, Brazil

\section{Introduction}

Brazil is the world champion lightning rays. Generated by its extension and continental characteristics. The Atmospheric Electricity Group (ELAT) of the National Institute for Space Research - INPE develops research on atmospheric electricity through experimental techniques, numerical modeling and theoretical studies. Emphasis is given to research on lightning in Brazil. Are estimated 57 million lightning strikes per year, where $70 \%$ occur in the months of January and February. There was a $79 \%$ increase in the number of stormy days in the last 60 years, compared with the first half of the 20th century. In the years 1910-1951, there were 43 days of storm, in 2010, that number jumped to 77 days. The cities that were most relevant data were São Paulo, Goiania, Manaus and Belém, with more than 100\% from 1910 to 2010 storms increases. INPE indicate that in 14 Brazilian cities, all with more than 50000 inhabitants and had significant population increase in recent 50 . Studies show that $70 \%$ of the rays fall on urban.

\section{Objectives}

Analyze on the state of São Paulo - Brazil, deaths by lightning second location, gender, age. Period 2010 to 2014.

\section{Methodology}

The analyzes were performed by the Technical Center staff Surveillance Epidmiological, using information from the National Institute for Space Research (INPE) and the State Secretaria of Health. Periods 2010 to 2014 were analyzed. This is a descriptive analysis, seeking identify key characteristics.

\section{Results}

At the 100 deaths that occur by lightning, $80 \%$ are rural. In 10 years, 1,702 people died from lightning in Brazil. $80 \%$ are men and $20 \%$ are women. Figures 1 and 2 shows the number of Death by Year (20002014) of occurrence and the age. The people with 25-59 years old, are the principal occurrence (Figures 1 and 2).

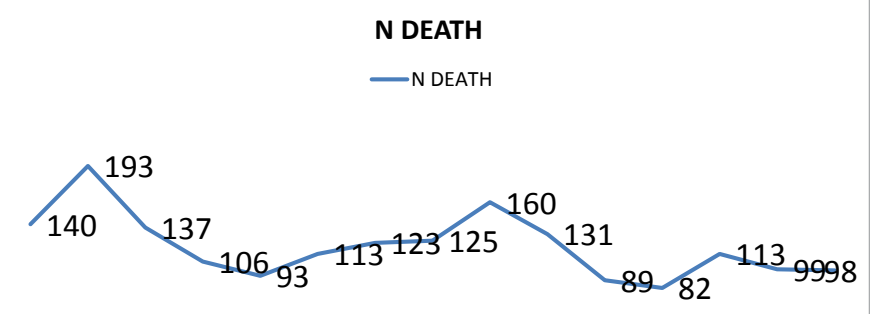

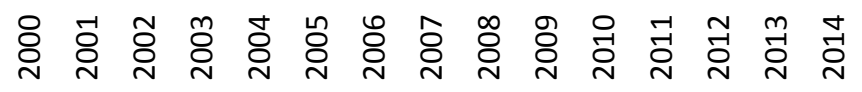

Figure 1: Death by Lightning in Brazil Years 2000 - 2014= 1702 people Source: INPE + MS

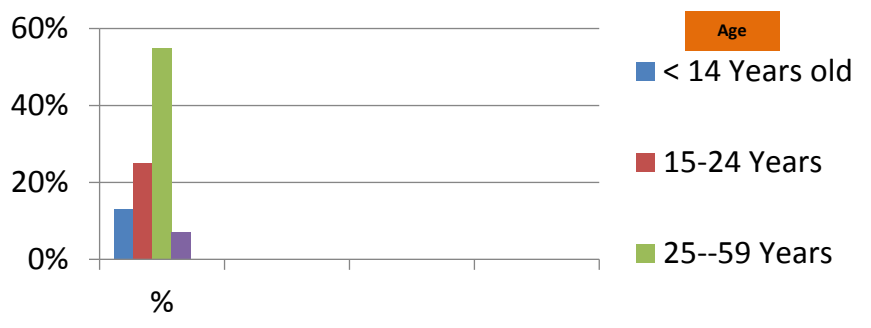

Figure 2: Number Death for age: $1702=2000$ a 2014 Source: INPE + MS

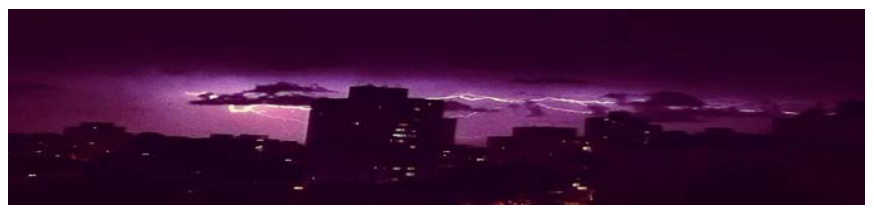

Figure 3: Photo by Rogerio Crhistensen.

\section{Conclusions}

The studies by INPE shows that the number of storms has increased in São Paulo and Campinas, in proportion to the growth of cities, which supports the idea that heat islands formed in urban areas are responsible for the increased rainfall. Studies by Secretary Health shows that number of death are important. Deaths by lightning decreases as the population becomes more aware of the risks, then it is important to analysis and dissemination (Figure 3).
*Corresponding author: Nery T, Secretary of state for health-Epidemiological Surveillance Center, Division of Diseases Caused by Environmental, SP, Brazil, Tel: 5511 3066-8767; E-mail: dvdoma@saude.sp.gov.br

Received February 24, 2015; Accepted June 17, 2015; Published June 24, 2015 Citation: Nery T, Pereira F, Christensen R (2015) Epidemiology of Deaths by Lightning in the State of Sao Paulo-Brazil Years 2000 to 2014, and Impacts of Development and Environmental Factors. J Climatol Weather Forecasting 3: 134. doi:10.4172/2332-2594.1000134

Copyright: (c) 2015 Nery T, et al. This is an open-access article distributed under the terms of the Creative Commons Attribution License, which permits unrestricted use, distribution, and reproduction in any medium, provided the original author and source are credited. 